\title{
Antioxidant Activity of Novel Indole Derivatives and Protection of the Myocardial Damage in Rabbits
}

\author{
Ioanna Andreadou, ${ }^{a}$ Androniki Tasouli, ${ }^{b}$ Elias Bofilis, ${ }_{b}^{b}$ Michael ChrYsselis, ${ }^{c}$ Eleni ReKKa, ${ }^{c}$ \\ Anna Tsantili-Kakoulidou, ${ }^{*, a}$ Efstathios Iliodromitis, ${ }^{b}$ Theodora Siatra, ${ }^{a}$ and \\ Dimitrios Thoma KREMASTINOs ${ }^{b}$
}

Department of Pharmaceutical Chemistry, School of Pharmacy, University of Athens, ${ }^{a}$ Panepistimioupolis, Zografou, Athens 157-71, Greece, Second Department of Cardiology, Onassis Cardiac Surgery Center, ${ }^{b} 356$ Syngrou Avenue, 17674, Athens, Greece, and Department of Medicinal Chemistry, School of Pharmacy, Aristotelian University of Thessaloniki, ${ }^{c}$ 54006 Thessaloniki, Greece. $\quad$ Received July 16, 2001; accepted November 16, 2001

\begin{abstract}
Novel indole derivatives containing a triazole moiety $(1 \mathrm{a}-\mathrm{d}, \mathbf{2 a}-\mathrm{c})$ were synthesized as lead compounds with interesting pharmacological profiles. Their antioxidant activity was investigated on in vitro non-enzymatic rat hepatic microsomal lipid peroxidation. All compounds showed significant effect in the above assay. The effect depended mainly on the attachment position of the triazole moiety on the indole nucleus. The most potent antioxidant derivatives $1 \mathrm{a}, 1 \mathrm{c}$ and $1 \mathrm{~d}$ were tested for their protective ability against the oxidative damage of the myocardium after ischemia-reperfusion, in male rabbits which were subjected to $30 \mathrm{~min}$ regional ischemia followed by reperfusion. The tested antioxidant compounds $1 \mathrm{a}, 1 \mathrm{c}$ and $1 \mathrm{~d}$ were continuously infused for $30 \mathrm{~min}$ starting at 10th min of ischemia and lasted at 10th min of reperfusion. The concentration of malondialdehyde (MDA, a marker of lipid peroxidation) and hemodynamic parameters (blood pressure and heart rate) were measured in the baseline, at 20th min of the sustained ischemia, 1st and 20th min of reperfusion. It was found that the examined compounds 1a, 1c and 1d reduced significantly the level of MDA in rabbits under ischemia-reperfusion and proved to be promising substances for further evaluation of anti-ischemic properties.
\end{abstract}

Key words antioxidant activity; indole derivative; lipid peroxidation; myocardial infarction; malondialdehyde

In the last years, there is increasing evidence of the implication of free radicals and reactive oxygen species in a variety of diseases and pathophysiological events including inflammation, cancer, myocardial infarction, arthritis and neurodegenerative disorders. ${ }^{1-3)}$ Reactive oxygen species (ROS) have been suggested to play an important role in the pathophysiology of myocardial reperfusion injury. They may cause initiation of lipid peroxidation, direct inhibition of mitochondrial respiratory chain enzymes, inactivation of glyceraldehyde-3-phosphate dehydrogenase, inhibition of membrane sodium/potassium ATPase activity, inactivation of membrane sodium channel and other oxidative modifications of proteins. All these toxic effects are likely to play a role in the pathophysiology of shock, inflammation and ischemia-reperfusion injury. ${ }^{4)}$

During post-ischemic reperfusion, oxygen enters the cell at high tension (increased flow) combining with hypoxanthine in the presence of xanthine oxidase. This results in the generation of superoxide anions and other free radicals that cause widespread lipid peroxidation and damage to cellular membranes. ${ }^{5)}$

Therefore considerable research interest is focused on the investigation of the antioxidant properties of pharmacologically active compounds and several experimental protocols have been developed for this purpose.

In the design of new drugs, the development of hybride molecules through the combination of different pharmacophores in one frame may lead to compounds with interesting pharmacological profiles. It is well documented that the five membered heterocycles exhibit anti-inflammatory, ${ }^{6,7)}$ antiviral $^{8)}$ and antimicrobial ${ }^{9)}$ activities. On the other hand, antidepressive, ${ }^{10)}$ antiallergic, ${ }^{11)}$ antimicrobial ${ }^{12)}$ and anti-ischemic properties have been reported to be associated with the indolic nucleus, while it incorporates a considerable an- tioxidant potential. ${ }^{13,14)}$ The combination of these two pharmacophores in the same molecule is an interesting challenge for the development of new pharmacologically active antioxidants.

We have previously reported on the synthesis and pharmacological properties of new indolic derivatives, bearing a thiosemicarbazide moiety, as well as their cyclic triazole analogues. ${ }^{15,16)}$ These compounds were shown to have significant antioxidant properties as resulted from their ability to scavenge hydroxyl radicals ( $(\mathrm{OH})$ and to interact with $\alpha, \alpha$ diphenyl- $\beta$-picrylhydrazyl (DPPH) stable radical. ${ }^{17)}$ They presented however solubility problems due to the presence of highly hydrophobic substituents on the thiosemicarbazide or triazole moiety. Therefore they could not be used for further in vivo investigation. In order to circumvent these unfavorable structural characteristics, we considered it of interest to synthesize some novel less lipophilic indole-triazole derivatives with the benefit to be suitable for in vivo experiments. The new compounds were investigated for their antioxidant and potential anti-ischemic activity.

Chemistry The structures of the new compounds are presented in Table 1. The triazole moiety is connected via a methylene bridge on the indole nucleus, either at position N1 (Type 1), or at position C3 (Type 2) and bears a free amino group at N4. Compounds differentiate also in substitution at position 5 of the indole nucleus.

The compounds were synthesized upon reaction of the appropriate hydrazides with carbon disulfide and cyclization of the obtained carbazinates with hydrazine hydrate. The synthetic route is depicted in Chart 1.

\section{Results and Discussion}

It is well known that the re-introduction of oxygen to ischemic and hypoxic heart is associated with free radicals 
Table 1. Structures of the Synthesized Compounds<smiles>[Y]c1ccc2[nH]c([R])cc2c1</smiles>

\begin{tabular}{ccccc}
\hline \hline Compound & $\begin{array}{c}\text { Position of the } \\
\text { triazole moiety }\end{array}$ & $\mathrm{X}$ & $\mathrm{R}$ & $n$ \\
\hline $\mathbf{1 a}$ & 1 & $\mathrm{H}$ & $\mathrm{H}$ & 1 \\
$\mathbf{1 b}$ & 1 & $\mathrm{Br}$ & $\mathrm{H}$ & 1 \\
$\mathbf{1 c}$ & 1 & $\mathrm{Cl}$ & $\mathrm{H}$ & 1 \\
$\mathbf{1 d}$ & 1 & $\mathrm{NO}_{2}$ & $\mathrm{H}$ & 1 \\
$\mathbf{2 a}$ & 3 & $\mathrm{H}$ & $\mathrm{H}$ & 1 \\
$\mathbf{2 b}$ & 3 & $\mathrm{H}$ & $\mathrm{H}$ & 2 \\
$\mathbf{2 c}$ & 3 & $\mathrm{H}$ & $\mathrm{CH}_{3}$ & 1 \\
\hline
\end{tabular}

Table 2. The Percent Inhibition of the Examined Compounds of Lipid Peroxidation in Various Concentrations after $45 \mathrm{~min}$ of Incubation, against Control $^{a)}$

\begin{tabular}{crrrr}
\hline \hline & \multicolumn{4}{c}{ \% Inhibition } \\
\cline { 2 - 5 } Compound & $1 \mathrm{~mm}$ & $0.5 \mathrm{mM}$ & $0.25 \mathrm{mM}$ & $0.05 \mathrm{~mm}$ \\
\hline $\mathbf{1 a}$ & 100 & 100 & 100 & 96 \\
$\mathbf{1 b}$ & 99 & 99 & 98 & 6 \\
$\mathbf{1 c}$ & 98 & 98 & 98 & 97 \\
$\mathbf{1 d}$ & 99 & 98 & 98 & 98 \\
$\mathbf{2 a}$ & 98 & 98 & 98 & 24 \\
$\mathbf{2 b}$ & 100 & 97 & 73 & 5 \\
$\mathbf{2 c}$ & 100 & 97 & 97 & 42 \\
DL- $(\alpha)$-Tocopherol acetate & 100 & 9 & & \\
\hline
\end{tabular}

a) Based on absorbance values of samples with the tested compounds against controls containing equal volume of the solvent. Standard deviation of absorbance values was less than $\pm 10 \%, n=3$.

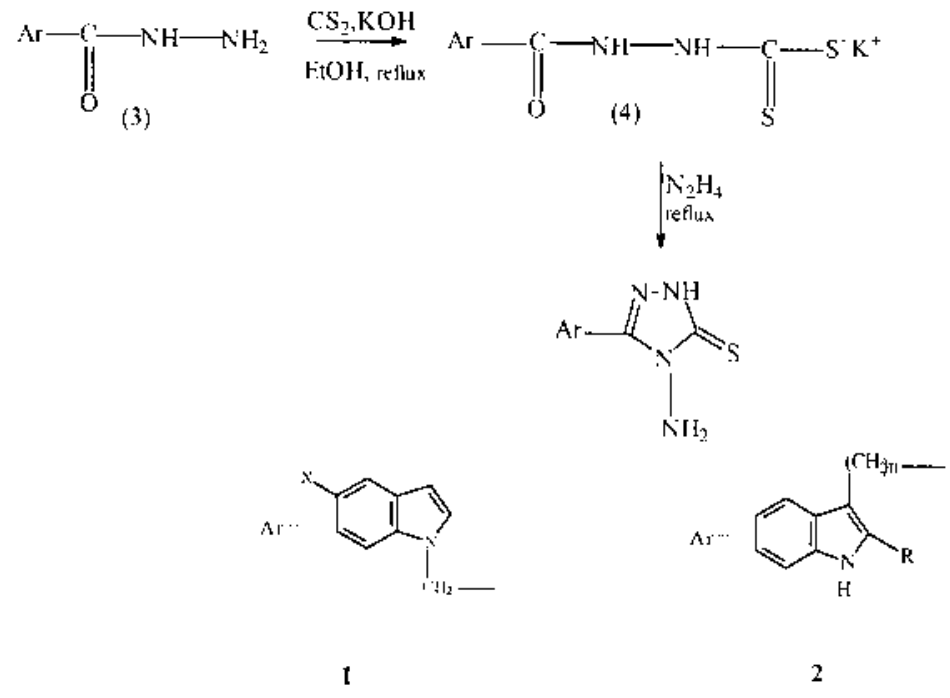

Chart 1. Synthetic Route Followed for the Preparation of the Compounds $\mathbf{1}$ and $\mathbf{2}$

production that causes profound membrane disrupting and contributes to arrhythmia and to stunning. This phenomenon is called reperfusion injury and should be avoided by the use of agents, which act as free radical scavengers. ${ }^{18,19)}$

Lipid peroxidation consists of a radical-initiated reaction and can serve for the evaluation of the antioxidant properties of substances. Agents with antioxidant properties are expected to have some beneficial effects on the ischemic or ischemic/reperfused myocardium. ${ }^{20)}$

The synthesized compounds were tested on in vitro nonenzymatic lipid peroxidation of rat hepatic microsomal membranes by measurement of the formation of 2-thiobarbituric acid reactive substances and the results are summarized in Table 2.

All the tested compounds showed significant effect on the inhibition of lipid peroxidation. At a concentration of $0.25 \mathrm{~mm}$ all compounds inhibited lipid peroxidation more than $97 \%$, with the exception of compound $\mathbf{2 b}$, that showed a $73 \%$ inhibition. These findings become more interesting, considering that the reference compound DL- $(\alpha)$-tocopherol acetate becomes inactive at a concentration of $0.5 \mathrm{~mm}^{21)}$ At a concentration of $0.05 \mathrm{~mm}$, inhibition was reduced for compounds of type 2 , indicating the importance of the attach- ment position of the triazole moiety on the indolic nucleus. A possible explanation may be based on the differentiation in the molecular conformation, between the $\mathrm{N} 1$ and $\mathrm{C} 3$ substituted derivatives. The size of the carbon atom bridge may also interfere in the activity, since the decrease in activity is more evident for compound $\mathbf{2 b}$. Compound $\mathbf{1 b}$ with a bromine substitution at position $\mathrm{C} 5$ of the indolic nucleus also looses activity at a concentration of $0.05 \mathrm{~mm}$. Compounds 1a, 1c and 1d however, kept their high inhibitory activity even at this low concentration.

According to the above results, in vivo experiments in rabbits were performed with compounds 1a, 1c and 1d. The aim of the in vivo experiment was to monitor myocardial malondialdehyde (MDA) levels as an index of lipid peroxidation during ischemia/reperfusion.

Preliminary toxicity studies showed that these compounds are not toxic at a concentration of $100 \mu \mathrm{M}$. Thus, the dose was set up at $100 \mu \mathrm{M} / \mathrm{kg} \mathrm{BW}$ and the compounds were administered by infusion continuously for $30 \mathrm{~min}$ starting at 10th min of ischemia and lasted at 10th min of reperfusion. It is reported that the increase in MDA level can be observed during ischemia and at an early period of reperfusion, but may be not detectable during a late period of reperfusion. ${ }^{22)}$ 
Table 3. Effect of the Tested Compounds on the Hemodynamic Parameters (MBP and HR), in Rabbits, at the Baseline, at the 20th min of the Sustained Ischemia, at the 1 st min of Reperfusion and at the 20th min of Reperfusion $^{a}$ )

\begin{tabular}{ccccc}
\hline \hline $\begin{array}{c}\text { Treatment } \\
\text { parameter }\end{array}$ & Baseline & $\begin{array}{c}\text { 20th min } \\
\text { ischemia }\end{array}$ & $\begin{array}{c}\text { 1st min } \\
\text { reperfusion }\end{array}$ & $\begin{array}{c}\text { 20th min } \\
\text { reperfusion }\end{array}$ \\
\hline $\begin{array}{c}\text { Normal saline }(n=5) \\
\text { MBP (mmHg) }\end{array}$ & $119 \pm 8.3$ & $103 \pm 3.7$ & $91 \pm 5.1$ & $94 \pm 4.8$ \\
HR (beats/min) & $229 \pm 10.8$ & $228 \pm 8.6$ & $234 \pm 10.3$ & $234 \pm 9.3$ \\
1a $(n=7)$ & & & & \\
MBP (mmHg) & $103 \pm 5.8$ & $86 \pm 6.4$ & $81 \pm 5.6$ & $82 \pm 6.9$ \\
HR (beats/min) & $289 \pm 11.1$ & $282 \pm 9.3$ & $274 \pm 9.1$ & $281 \pm 9.4$ \\
1c $(n=5)$ & & & & \\
MBP (mmHg) & $113 \pm 5.7$ & $99 \pm 8.5$ & $92 \pm 8.1$ & $101 \pm 4.7$ \\
HR (beats/min) & $286 \pm 19.6$ & $285 \pm 29.7$ & $284 \pm 29.7$ & $290 \pm 12.6$ \\
1d $(n=5)$ & & & & \\
MBP (mmHg) & $111 \pm 5.3$ & $77 \pm 7.2$ & $71 \pm 7.5$ & $68 \pm 4.3^{b)}$ \\
HR (beats/min) & $282 \pm 8.6$ & $267 \pm 9.6$ & $270 \pm 8.4$ & $280 \pm 7.1$ \\
\hline
\end{tabular}

a) Data are means \pm S.E.M. b) $p<0.05$, compared with the MBP at the baseline.

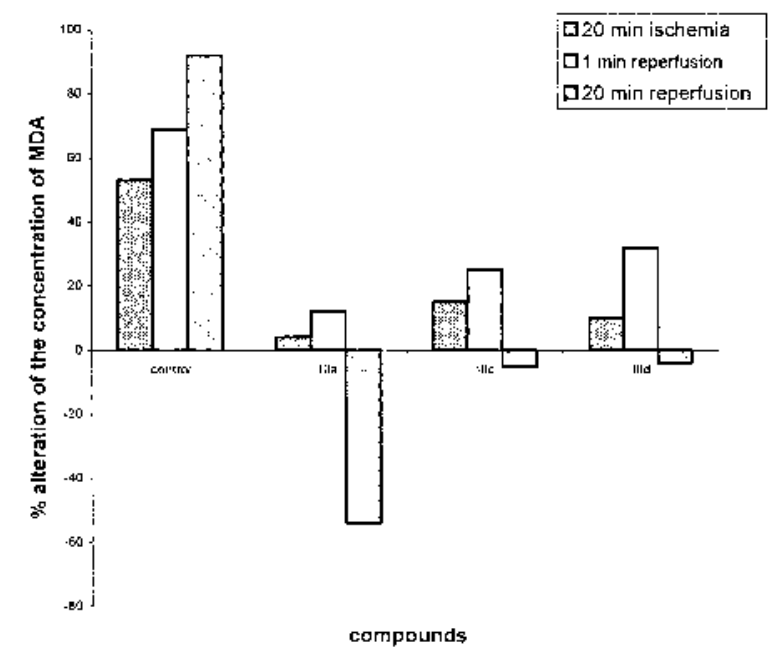

Fig. 1. Percent Alteration of MDA Concentration at 20th min of Ischemia, 1 st min of Reperfusion and 20th min of Reperfusion

Thus, MDA levels were determined in blood at baseline, 20th min of ischemia, 1st and 20th min of reperfusion.

The control group $(n=5)$ received normal saline and no difference was observed in the heart rate (HR) and mean blood pressure (MBP) until the 20th min of reperfusion (Table 3). In the groups treated with the compounds 1a $(n=7)$ and 1c $(n=5)$ no effect on HR and MBP of the rabbits was observed in comparison with the baseline. Statistically significant difference in the MBP was recorded in the group treated with compound $\mathbf{1 d}$ in the 20th min of reperfusion, compared to the baseline.

The percentage of alteration in MDA concentration is illustrated in Fig. 1. The MDA production in the control group followed the anticipated protocol increasing by $53 \%$ at the 20th min of ischemia, by $69 \%$ at the 1 st minute of reperfusion and by $92 \%$ at the 20th minute of reperfusion. On the contrary, after treatment with the tested compounds, the alteration of MDA concentration was obviously lower than that observed in the control group at the 20th min of ischemia and the 1 st min of reperfusion. At the 20th min of reperfusion MDA alteration reached the levels of the baseline for the groups treated with compounds $\mathbf{1 c}$ and $\mathbf{1 d}$. It should be noted
Table 4. Levels of the MDA Concentration in the Baseline, and at the 20th min of Reperfusion ${ }^{a}$

\begin{tabular}{cccc}
\hline \hline Treatment & $n^{b)}$ & $\begin{array}{c}\text { MDA } \\
(\mu \mathrm{M} \text { at baseline })\end{array}$ & $\begin{array}{c}\text { MDA } \\
(\mu \mathrm{M} \text { at 20 min reperfusion })\end{array}$ \\
\hline Normal saline & 5 & $2.45 \pm 0.28$ & $4.70 \pm 0.35^{c)}$ \\
1a & 7 & $2.12 \pm 0.33$ & $0.97 \pm 0.13^{c, d)}$ \\
1c & 5 & $1.82 \pm 0.23$ & $1.73 \pm 0.09^{d)}$ \\
Id & 5 & $2.60 \pm 0.50$ & $2.50 \pm 0.47^{d)}$
\end{tabular}

a) Data are means \pm S.E.M. Measurements of each group have been performed in triplicate. b) $n$, Number of animals. c) $p<0.05$, compared with the baseline. d) $p<0.05$, compared with the control group.

that compound 1a produced a further reduction of $53 \%$ in MDA levels (Fig. 1). This result may be considered to reflect a more beneficial effect of compound 1a on the myocardial damage.

The means \pm S.E.M. of MDA concentration at the baseline and at the 20th min of reperfusion in controls and in groups of animals treated with compounds $\mathbf{1 a}, \mathbf{1 c}$ and $\mathbf{1 d}$ are shown in Table 4. The increase in MDA level in the control group is statistically significant compared to the baseline. The reduction of MDA levels produced by the tested compounds is statistically significant compared to the controls. Moreover, compound $\mathbf{1 a}$ produced a statistically significant decrease in MDA concentration at the 20th min of reperfusion compared to the baseline.

These findings suggest that the three compounds exert significant antioxidant activity in vivo and possess protective effect against damaged myocardium. This effect is more evident for compound $\mathbf{1 a}$.

In conclusion, all tested compounds showed significant antioxidant properties in vitro by inhibiting lipid peroxidation in rat liver microsomes at very low concentrations. Compounds 1a, 1c and 1d can protect rabbit myocardium from ischemia-reperfusion injury in vivo, in a clinically based experimental protocol. In addition, 1a and 1c agents do not interfere with hemodynamic parameters. Compound 1a with no substitution at position $\mathrm{C} 5$ of the indolic nucleus has the simplest structure and could be considered as a promising agent for further evaluation of the mechanism of antioxidant activity and anti-ischemic properties.

\section{Experimental}

All reagents were purchased from Aldrich Chemical Company (Gillingam, Dorset U.K.). The solvents were supplied by Labscan Ltd. (Unit T26, Dublin Ireland).

Melting points were taken in glass capillary tubes on a Buchi 530 apparatus and are not corrected. Infrared (IR) spectra were run as potassium bromide disks on a Perkin-Elmer 883 spectrophotometer. The nuclear magnetic resonance spectra ( $\left.{ }^{1} \mathrm{H}-\mathrm{NMR}\right)$ were recorded on a Bruker AC200 spectrometer. Chemical shifts $(\delta)$ are expressed in ppm relative to tetramethylsilane (TMS) as an internal standard. Elemental analyses were carried out by Service Centrale de Microanalyses of CNRS in Vernaison France and the experimental values were within $\pm 0.4 \%$ of the theoretical values.

General Procedure for the Preparation of Potassium 1-Indolylmethyl and 3-Indolylalkyl Dithiocarbazinates (4) Potassium hydroxide $(0.15 \mathrm{~mol})$ was dissolved in absolute ethanol $(60 \mathrm{ml})$. To the above solution the suitable hydrazide (3) $(0.1 \mathrm{~mol})$, prepared as described previously, $\left.{ }^{15}\right)$ was added and cooled in ice. To this mixture carbon disulfide $(0.1 \mathrm{~mol})$ was added, the reaction was stirred at room temperature for $24 \mathrm{~h}$ and then cooled and diluted with anhydrous ether $(100 \mathrm{ml})$. The produced potassium dithiocarbazinate was filtered, washed with anhydrous ether and then dried in vacuum. Potassium dithiocarbazinates were obtained in quantitative yield and used for the preparation of the corresponding triazoles without further purification, as they were moisture sensitive. 
General Procedure for the Preparation of 3-[(5-Substituted-1H-1-indolyl)methy]-4-amino-4,5-dihydro-1H-1,2,4-triazole-5-thione (1a-d), 3[(1H-3-Indolyl)methyl or ethyl]-4-amino-4,5-dihydro- $1 H$-1,2,4-triazole5-thione $(2 \mathrm{a}-\mathrm{b})$ and 3-[(2-Methyl-1H-3-indolyl)methyl])-4-amino-4,5dihydro-1H-1,2,4-triazole-5-thione (2c) Potassium 1- or 3-indolylalkyl dithiocarbazinate $(4)(0.1 \mathrm{~mol})$ was suspended in water $(5 \mathrm{ml})$. To this suspension hydrazine hydrate $(0.25 \mathrm{~mol})$ was added and the reaction mixture was refluxed with stirring for $4 \mathrm{~h}$. The mixture was cooled, water was added $(80 \mathrm{ml})$ and the mixture was acidified with $10 \%$ acetic acid. The white precipitate was filtered, washed with water, dried in vacuum and crystallized from ethanol.

1a: White powder, $\mathrm{mp} 208-210^{\circ} \mathrm{C}$, IR $(\mathrm{KBr}) \mathrm{cm}^{-1}: 3275,1380,1230$, ${ }^{1} \mathrm{H}-\mathrm{NMR}\left(200 \mathrm{MHz}, \mathrm{DMSO}-d_{6}\right) \delta: 3.87(2 \mathrm{H}, \mathrm{s}), 6.34(1 \mathrm{H}, \mathrm{d}), 6.54(1 \mathrm{H}, \mathrm{d})$, 6.88-7.45 (4H, m,). Anal. Calcd for $\mathrm{C}_{11} \mathrm{H}_{11} \mathrm{~N}_{5} \mathrm{~S}: \mathrm{C}, 53.86 ; \mathrm{H}, 4.52$. Found: C, $53.70 ; \mathrm{H}, 4.38$.

1b: White powder, $\mathrm{mp} 195-198^{\circ} \mathrm{C}, \mathrm{IR}(\mathrm{KBr}) \mathrm{cm}^{-1}: 3280,1360,1228$, ${ }^{1} \mathrm{H}-\mathrm{NMR}\left(200 \mathrm{MHz}\right.$, DMSO- $\left.d_{6}\right) \delta: 4.35(2 \mathrm{H}, \mathrm{s}), 6.34(1 \mathrm{H}, \mathrm{d}), 6.50(1 \mathrm{H}, \mathrm{d})$, $6.99(1 \mathrm{H}, d), 7.20(1 \mathrm{H}, \mathrm{dd}), 7.55(1 \mathrm{H}, \mathrm{d})$. Anal. Calcd for $\mathrm{C}_{11} \mathrm{H}_{10} \mathrm{~N}_{5} \mathrm{BrS}: \mathrm{C}$, 40.74; H, 3.10. Found: C, 40.38; H, 3.25.

1c: White powder, $\mathrm{mp} 200-203^{\circ} \mathrm{C}, \mathrm{IR}(\mathrm{KBr}) \mathrm{cm}^{-1}: 3370,1350,1220$, ${ }^{1} \mathrm{H}-\mathrm{NMR}\left(200 \mathrm{MHz}, \mathrm{DMSO}-d_{6}\right) \delta: 4.20(2 \mathrm{H}, \mathrm{s}), 6.34(1 \mathrm{H}, \mathrm{d}), 6.54(1 \mathrm{H}, \mathrm{d})$, $6.89(1 \mathrm{H}, \mathrm{d}), 7.20(1 \mathrm{H}, \mathrm{dd}), 7.54(1 \mathrm{H}, \mathrm{d})$. Anal. Calcd for $\mathrm{C}_{11} \mathrm{H}_{10} \mathrm{~N}_{5} \mathrm{ClS}: \mathrm{C}$, 47.22; H, 3.60. Found: C, 47.40; H, 3.80 .

1d: White powder, $\mathrm{mp} 210-212{ }^{\circ} \mathrm{C}, \mathrm{IR}(\mathrm{KBr}) \mathrm{cm}^{-1}: 3280,1360,1223$, ${ }^{1} \mathrm{H}-\mathrm{NMR}\left(200 \mathrm{MHz}\right.$, DMSO- $\left.d_{6}\right) \delta: 4.5(2 \mathrm{H}, \mathrm{s}), 6.34(1 \mathrm{H}, \mathrm{d}), 6.54(1 \mathrm{H}, \mathrm{d})$, $6.85(1 \mathrm{H}, \mathrm{d}), 7.12(1 \mathrm{H}, \mathrm{dd}), 7.55(1 \mathrm{H}, \mathrm{d})$. Anal. Calcd for $\mathrm{C}_{11} \mathrm{H}_{10} \mathrm{~N}_{6} \mathrm{O}_{2} \mathrm{~S}$, $\mathrm{H}_{2} \mathrm{O}: \mathrm{C}, 42.84 ; \mathrm{H}, 3.92$. Found: $\mathrm{C}, 42.85 ; \mathrm{H}, 3.89$.

2a: White powder, $\mathrm{mp} 218-220^{\circ} \mathrm{C}, \mathrm{IR}(\mathrm{KBr}) \mathrm{cm}^{-1}: 3300,1380,1250$, ${ }^{1} \mathrm{H}-\mathrm{NMR}\left(200 \mathrm{MHz}, \mathrm{DMSO}-d_{6}\right) \delta$ : $3.87(2 \mathrm{H}, \mathrm{s}), 6.88(1 \mathrm{H}, \mathrm{s}), 7.10-7.56$ $(4 \mathrm{H}, \mathrm{m}), 10.67(1 \mathrm{H}, \mathrm{s})$. Anal. Calcd for $\mathrm{C}_{11} \mathrm{H}_{11} \mathrm{~N}_{5} \mathrm{~S}: \mathrm{C}, 53.86 ; \mathrm{H}, 4.52$. Found: C, 54.00; H, 4.17.

2b: White powder, $\mathrm{mp} 154-156^{\circ} \mathrm{C}, \mathrm{IR}(\mathrm{KBr}) \mathrm{cm}^{-1}: 3300,1390,1210$, ${ }^{1} \mathrm{H}-\mathrm{NMR}\left(200 \mathrm{MHz}, \mathrm{CDCl}_{3}\right) \delta: 0.80(2 \mathrm{H}, \mathrm{t}), 1.20(2 \mathrm{H}, \mathrm{t}), 6.54(1 \mathrm{H}, \mathrm{s})$, $7.00-7.45(4 \mathrm{H}, \mathrm{m})$. Anal. Calcd for $\mathrm{C}_{12} \mathrm{H}_{13} \mathrm{~N}_{5} \mathrm{~S}: \mathrm{C}, 55.57$; H, 5.05. Found: C, $55.95 ; \mathrm{H}, 4.76$.

2c: White powder, $\mathrm{mp} 156-158^{\circ} \mathrm{C}, \mathrm{IR}(\mathrm{KBr}) \mathrm{cm}^{-1}: 3375,1385,1226$, ${ }^{1} \mathrm{H}-\mathrm{NMR}\left(200 \mathrm{MHz}, \mathrm{CDCl}_{3}\right) \delta: 1.72(3 \mathrm{H}, \mathrm{s}), 3.87(2 \mathrm{H}, \mathrm{s}), 7.10-7.53(4 \mathrm{H}$, m). Anal. Calcd for $\mathrm{C}_{13} \mathrm{H}_{15} \mathrm{~N}_{5} \mathrm{~S}: \mathrm{C}, 55.36 ; \mathrm{H}, 5.38$. Found: C, 55.76; H, 5.18.

Pharmacology Materials Reagents for biochemical assays were purchased from Sigma Aldrich Chemie, Steinheim, Germany and were of analytical grade.

Animals Male Wistar rats weighing 250-300g and New Zealand White male rabbits weighing $1.4-2.5 \mathrm{~kg}$ were used. All animals received proper care in compliance with the "Principles of Laboratory Animal Care" formulated by the National Academy of Sciences and published by the National Institutes of Health (NIH publication no. 86-23, revised 1985).

In Vitro Lipid Peroxidation For the in vitro lipid peroxidation, heat inactivated hepatic microsomal fraction from untreated male Wistar rats, corresponding to $0.125 \mathrm{~g}$ liver $/ \mathrm{ml}$ was used. Lipid peroxidation was induced by the $\mathrm{Fe}^{2+}(10 \mu \mathrm{m}) /$ ascorbic acid $(0.2 \mathrm{~mm})$ system. The tested compounds were dissolved in dimethyl sulphoxide (DMSO) and added $(100 \mu \mathrm{l})$ to the incubation mixture (final volume $4 \mathrm{ml}$, in Tris- $\mathrm{HCl} / \mathrm{KCl} 50 \mathrm{~mm} / 150 \mathrm{~mm}$ buffer solution, $\mathrm{pH} 7.4)$ at various concentrations $(1-0.05 \mathrm{~mm})$. The mixture was incubated at $37^{\circ} \mathrm{C}$ for $45 \mathrm{~min}$. Lipid peroxidation was determined spectrophotometrically at $535 \mathrm{~nm}$ against $600 \mathrm{~nm}$ using a Perkin-Elmer Lambda 7 UV/VIS spectrophotometer. ${ }^{21,23)}$ All compounds and dimethyl sulfoxide (DMSO) were tested and found not to interfere with the assay. Each experiment was performed at least in triplicate. DL- $(\alpha)$ tocopherol acetate was used as reference compound.

Protective Effect of the Synthesized Compounds against the Oxidative Damage of the Heart after Ischemia-Reperfusion in Rabbits Surgical Preparation: All animals were anesthesized by slowly injecting pentobarbital $(30 \mathrm{mg} / \mathrm{kg})$ into an ear vein. Then, they were subjected to tracheal incision and intubation for mechanical ventilation with a respirator for small animals (MD Industries, Mobile, AL, U.S.A.). The ventilator was properly adjusted at a rate of approximately 35 respirations $/ \mathrm{min}$, in an attempt to maintain blood gases and $\mathrm{pH}$ within the normal range. Two polyethylene catheters were inserted; one was positioned in the carotid artery for continuous blood pressure monitoring, and the other in the jugular vein for fluid infusion $(1 \mathrm{ml}$ of normal saline containing $1000 \mathrm{IU}$ heparin $/ 100 \mathrm{ml}$ was administered every $30 \mathrm{~min}$ ), drug administration, and additional anesthesia when necessary. A bipolar chest lead was used for continuous electro-cardiographic recording. Blood pressure and heart rate were continuously monitored. The chest was opened via a left thoracotomy in the fourth intercostal space and, after peri- cardiotomy, the beating heart was exposed. A 3-0 silk thread was passed through the myocardium around a prominent branch of the left anterior descending coronary artery and regional ischemia was induced by pulling the ends of the suture through a small segment of a soft tube; the tube was then firmly attached against the artery with a clamp. The successful induction of ischemia was verified by visual inspection (cyanosis) and by ST elevation on the electrocardiogram. Reperfusion was achieved by unclamping the tube. ${ }^{24)}$

Experimental Protocol: Rabbits were randomly divided in one control group $(n=5)$ that received normal saline and to groups treated with the synthesized compounds. After the period of hemodynamic stabilization rabbit hearts were assigned to $30 \mathrm{~min}$ of sustained ischemia followed by reperfusion.

A solution of $100 \mu \mathrm{M} / \mathrm{kg} / \mathrm{BW}$ of the tested compound was continuously infused via jugular vein for $30 \mathrm{~min}$ starting at 10 th $\mathrm{min}$ of ischemia and lasted at 10 th min of reperfusion. The control group was subjected to $30 \mathrm{~min}$ of regional ischemia followed by reperfusion and received an infusion of normal saline for same time as previously described.

Blood samples were taken at baseline, 10th min after drug administration (20th min of ischemia), 1st and 20th min of reperfusion. MDA concentration was determined spectrophotometrically at $586 \mathrm{~nm}$ and expressed as $\mu \mathrm{M}(\mathrm{Ox}-$ ford Biomedical Research Colorimetric Assay for lipid peroxidation). ${ }^{25)}$ Measurements of each group have been performed in triplicate, and standard deviation was less than $\pm 10 \%$.

Statistical Analysis All results are presented as means \pm standard error (S.E.M.). Data were compared by one way analysis of variance (ANOVA) with Bonferroni and with Dunkan post hoc analysis. Statistical significance was set up at a value of $p<0.05$.

\section{References}

1) Bast A., Haenen G., Doelman C., Am. J. Med., 92 (Suppl. 3C), 2S13S (1991).

2) Bulkley G. B., Surgery, 113, 479-483 (1993).

3) Halliwell B., Gutteridge M., "Free radicals in Biology and Medicine," Third edition, Oxford Science Publications, Oxford University Press, 1998.

4) Cuzzocrea S., Riley D. P., Caputi A. P., Salvemini D., Pharmacol. Rev., 53, 135-159 (2001).

5) Sinatra S. T., De Marco J., Connecticut Medicine, 59, 579-588 (1995).

6) Mullican M. D., Wilson M. W., Connor D. T., Kostlan C. R., Shrier D. J., Dyer R. D., J. Med. Chem., 36, 1090-1099 (1993).

7) Boschelli D. H., Connor D. T., Bornemeier D. A., Dyer R. D,, Kennedy J. A., Kuipers P. J., Okonkwo G. C., Shrier D. J., Wright C. D., J. Med. Chem., 36, 1802-1810 (1993).

8) Witkowski J. T., Robins R. K., Khare G. P., Sidwell R. W., J. Med. Chem., 16, 935-937 (1973).

9) Shams El-Dine S. A., Hazzaa A. A. B., Pharmazie, 29, 761-768 (1974).

10) Krishna C., Joshi K. C., Chand P., Pharmazie, 37, 1-12 (1982).

11) Unangst P. C., Connor D. T., Stabler S. R., Weikert R. J., Carethers M. E., Kennedy J. A., Thueson D. O., Chestnut J. C., Adolphson R. L., Conroy M. C., J. Med. Chem., 32, 1360-1366 (1989).

12) Canoira L., Gonzalo Rodriguez J., Subirats J. B., Escario J.-A., Jimenez I., Martinez-Fernandez A. R., Eur. J. Med. Chem., 24, 39- 42 (1989).

13) Kaneko S., Okumura K., Numaguchi Y., Matsui H., Murase K., Mokumo S., Morishima I., Hira K., Toki Y., Ito T., Hayakawa T., Life Sci., 67, 101-112 (2000).

14) Liu F., Ng T. B., Biochem. Cell Biol., 78, 447-453 (2000).

15) Tsotinis A., Varvaresou A., Calogeropoulou Th., Siatra-Papastaikoudi Th., Tiligada Ai., Arzneim. Forsch./Drug Res., 47, 307-310 (1997).

16) Varvaresou A., Tsantili-Kakoulidou A., Siatra-Papastaikoudi T., Tiligada Ek., Arzneim. Forsch./Drug Res., 50, 48-54 (2000).

17) Andreadou I., Tsantili-Kakoulidou A., Siatra-Papastaikoudi Th., Res. Commun. Biochem. Cell Mol. Biol., 4, 269-276 (2000).

18) Manning A., Bernier M., Crome R., Little S., Hearse D., J. Mol. Cell. Cardiol., 20, 35-40 (1988).

19) Boli R., J. Am. Coll. Cardiol., 12, 239-249 (1988).

20) Kosugi T., Satoh K., Yamamoto A., Hoshi K., Aoki Y., Takagaki H., Ichihara K., J. Pharm. Sci., 89, 1114-1122 (2000).

21) Andreadou I., Rekka E., Demopoulos V. J., Bijloo G. J., Kourounakis P. N., Arzneim.-Forsch./Drug Res., 47, 643-647 (1997).

22) Ohmi H., Ichihara K., Abiko Y., Am. J. Physiol., 262, H553-H561 (1992).

23) Rekka E., Kolstee J., Timmerman H., Bast A., Eur. J. Med. Chem., 24, 43-54 (1989).

24) Iliodromitis E. K., Kremastinos D. Th., Katritsis D. G., Papadopoulos C. C., Hearse D. J., J. Mol. Cell Cardiol., 29, 915-920 (1997).

25) Janero D. R., Free Rad. Biol. Med., 9, 515-540 (1990). 